\title{
Association between urinary symptoms at 7 years old and previous urinary tract infection
}

\author{
A Hellström, E Hanson, S Hansson, $\mathrm{K}$ Hjälmås, U Jodal
}

\begin{abstract}
The association between current micturition habits and previous urinary tract infection was analysed among 3553 school entrants aged 7 years by means of a questionnaire. A high incidence of urinary infection, confirmed by urine culture, was found $(145(8.4 \%)$ in the 1719 girls and $32(1.7 \%)$ in the 1834 boys). There was a significant association between current symptoms that were suggestive of disturbed bladder function and previous urinary tract infection, but only among girls who were over 3 years of age at the time the first episode was diagnosed.
\end{abstract}

Urinary tract infections are common in children but the reason is often unknown. One factor of importance is inadequate emptying of the urinary bladder. ${ }^{1}$ Residual urine was a common finding among schoolgirls with asymptomatic bacteriuria, and recurrences after treatment occurred significantly more often in those who had more than $5 \mathrm{ml}$ of residual urine measured by an isotope technique. ${ }^{2}$ Residual urine was also common among girls with acute cystitis. ${ }^{3}$

Another important abnormality in children with recurrent urinary infections is poor coordination between the detrusor and the sphincter. ${ }^{4}$ Before the amount of residual urine is measured or urodynamic investigations are started, however, the symptoms of the child should be analysed. The most obvious symptom of bladder dysfunction is incontinence, which is associated with urinary infection. ${ }^{56}$ The incidence of other symptoms suggestive of bladder dysfunction is, however, not known. We therefore studied the association between current symptoms suggestive of bladder dysfunction and a history of previous urinary infections in an unselected group of 7 year old school entrants.

University of

Göteborg,

Sweden

Department of

Paediatric Surgery

A Hellström

E Hanson

K Hjälmås

Department of

Paediatrics

Paediatrics

U Jodal

Correspondence to:

Dr A Hellström,
Department of

Department of
Paediatric Surgery,

Paediatric Surgery

S-416 85 Göteborg

S-416 85

Sweden.

Accepted 21 August 1990 and the school nurse. Before this examination a health questionnaire is given to the families, to use as a basis for discussion. In 1982 an additional questionnaire about current micturition habits and urinary incontinence was given to all Swedish speaking school entrants in Göteborg by the school nurses. ${ }^{7}$ Previous urinary infections and other diseases of the urinary tract were also investigated. If there was anything abnor- mal or unanswered in the questionnaire the family was contacted by telephone for more details by one of the investigators. Children with problems were offered further examination at the children's hospital.

Nocturnal as well as diurnal incontinence was defined as wetting at least once during a three month period. Urgency was defined as a short latent period between the first sensation and the need to void that occurred daily. Children who were able to postpone micturition voluntarily while they were occupied were not considered to have urgency. A specific question was asked about the use of a squatting position to prevent incontinence (the 'curtsy' sign $^{8}$ ) and whether this was used at least once a week. A child was considered to have emptying difficulties when symptoms such as starting difficulties, poor or interrupted stream, straining or manual compression of the bladder, or prolonged micturition occurred more than twice a week.

The original records from hospitals and outpatient clinics of children who gave a history of urinary infections or other diseases of the urinary tract were studied, and the diagnosis of urinary tract infection re-evaluated. The growth of at least $10^{5}$ bacteria $/ \mathrm{ml}$ in voided urine, or any number in specimens of urine obtained by suprapubic aspiration, were required before the diagnosis of bacteriuria was made. A further classification of the infection was done according to clinical signs and laboratory findings. In children with fever of at least $38.5^{\circ} \mathrm{C}$ a diagnosis of acute pyelonephritis was made if the $C$ reactive protein concentration was $>20 \mathrm{mg} / \mathrm{l}$, or if the concentrating capacity was transiently decreased. ${ }^{9}$ The term 'cystitis' was used in children over 1 year of age with acute dysuria, temperature below $38.5^{\circ} \mathrm{C}$, and normal laboratory findings. Some children could not be classified according to these criteria-for example, when laboratory tests were normal or not carried out in children with fever and bacteriuria. These infections were diagnosed as 'unspecified urinary infections'. For 'asymptomatic bacteriuria' at least two urine cultures in which the same bacteria were grown, but in the absence of symptoms, were required.

Fisher's exact test was used for statistical analysis.

\section{Results}

In 1982 a total of 3627 Swedish speaking children born in 1975 entered school in Göteborg, and 3607 questionnaires were distributed. Of these $3556(98 \cdot 6 \%)$ were completed and returned, 48 refused to complete them, and 
three families had moved abroad. Three children with malformations were excluded (myelomeningocele, epispadia, and anal atresia with fistula to the urinary tract) leaving 3553 questionnaires for analysis (1719 girls and 1834 boys).

PREVIOUS URINARY TRACT INFECTIONS

Previous urinary tract infection was reported in 274 children, but from the original records, bacteriuria was confirmed in only 177: 145 girls and 32 boys (table 1). The median ages at the time of first infection were 4 years for girls and 0.8 years for boys. The infections were classified as acute pyelonephritis $(n=66)$, cystitis $(n=65)$, and asymptomatic bacteriuria $(n=11)$. In addition, there were 35 children whose infections could not be classified retrospectively (unspecified urinary infection). In the latter group, 21 children had had fever of $38.5^{\circ} \mathrm{C}$ or more but laboratory tests such as $\mathrm{C}$ reactive protein concentration and renal concentrating capacity were either normal or not carried out.

In 28 girls and 11 boys a diagnosis of urethritis had been made because of acute symptoms of micturition without appreciable bacterial growth. The remaining 58 children had been examined because of various symptoms and urine cultures had grown no pathogens.

BLADDER SYMPTOMS ASSOCIATED WITH PREVIOUS URINARY INFECTIONS

At least one symptom was reported by 919 of the 7 year old school entrants $(26 \%)$, the distribution being similar in both sexes. Isolated bed wetting occurred in 48 of the girls $(2 \cdot 8 \%)$ and 129 of the boys $(7 \cdot 0 \%)$. Isolated bed wetting did not correlate with a history of previous urinary infection. In contrast, girls with daytime wetting, urgency, squatting, and emptying difficulties had had previous urinary infections significantly more often than those without (table 2). Among the boys there was no such difference.

Among the girls with symptoms, previous

Table 1 Number (\%) of children who had had previous urinary tract infections according to sex and diagnosis

\begin{tabular}{llll}
\hline Diagnosis & Girls $(n=1719)$ & Boys $(n=1834)$ & $p$ Value \\
\hline Pyelonephritis & $47(2 \cdot 7)$ & $19(1 \cdot 0)$ & $<0 \cdot 001$ \\
Cystitis & $59(3 \cdot 4)$ & $6(0 \cdot 3)$ & $<0 \cdot 001$ \\
$\begin{array}{l}\text { Unspecified urinary } \\
\text { tract infection }\end{array}$ & $29(1 \cdot 7)$ & $6(0 \cdot 3)$ & $<0.001$ \\
$\begin{array}{l}\text { Asymptomatic } \\
\text { bacteriuria }\end{array}$ & $10(0 \cdot 6)$ & $1(0 \cdot 1)$ & $<0.01$ \\
\hline Total & $145(8 \cdot 4)$ & $32(1 \cdot 7)$ & $<0.001$
\end{tabular}

Table 2 Current symptoms in girls who did and did not have previous urinary tract infections

\begin{tabular}{|c|c|c|c|}
\hline & $\begin{array}{l}\text { No }(\%) \text { who had } \\
\text { previous urinary } \\
\text { tract infections } \\
(n=145)\end{array}$ & $\begin{array}{l}d N o(\%) \text { who } \\
\text { had not had } \\
\text { previous urinary } \\
\text { tract infections } \\
(n=1574)\end{array}$ & p Value \\
\hline $\begin{array}{l}\text { Isolated bed wetting } \\
\text { Daytime wetting } \\
\text { Urgency } \\
\text { Squatting } \\
\text { Emptying difficulties }\end{array}$ & $\begin{array}{l}1(0 \cdot 7) \\
31(21 \cdot 4) \\
46(31 \cdot 7) \\
15(10 \cdot 3) \\
8(5 \cdot 5)\end{array}$ & $\begin{aligned} & 47(3 \cdot 0) \\
& 72(4 \cdot 6) \\
& 314(19 \cdot 9) \\
& 26(1 \cdot 7) \\
& 14(0 \cdot 9)\end{aligned}$ & $\begin{array}{l}>0.05 \\
<0.001 \\
<0.01 \\
<0.001 \\
<0.001\end{array}$ \\
\hline
\end{tabular}

urinary infections had occurred most often in those with squatting (15 of 41) and emptying difficulties (eight of 22), 36\% in each group (fig 1). In girls with diurnal incontinence previous infection was reported by $31(30 \%)$ and in those with urgency by $46(13 \%)$. In contrast, only one of 48 girls (2\%) with isolated bed wetting had had a urinary infection. Seventeen of 74 girls with bed wetting combined with daytime symptoms $(23 \%)$, however, had had urinary infections.

The frequency of micturition did not differ between children with and without previous infections (mean 4.5 micturitions/day in each group).

AGE AT TIME OF FIRST URINARY INFECTION AND BLADDER SYMPTOMS

Of the girls who had infections during the first year of life, five (19\%) at age 7 had symptoms suggestive of bladder dysfunction compared with $18(49 \%)$ of those with first urinary infection at age 3 to 5 years $(\mathrm{p}<0.05)$ (fig 2$)$.

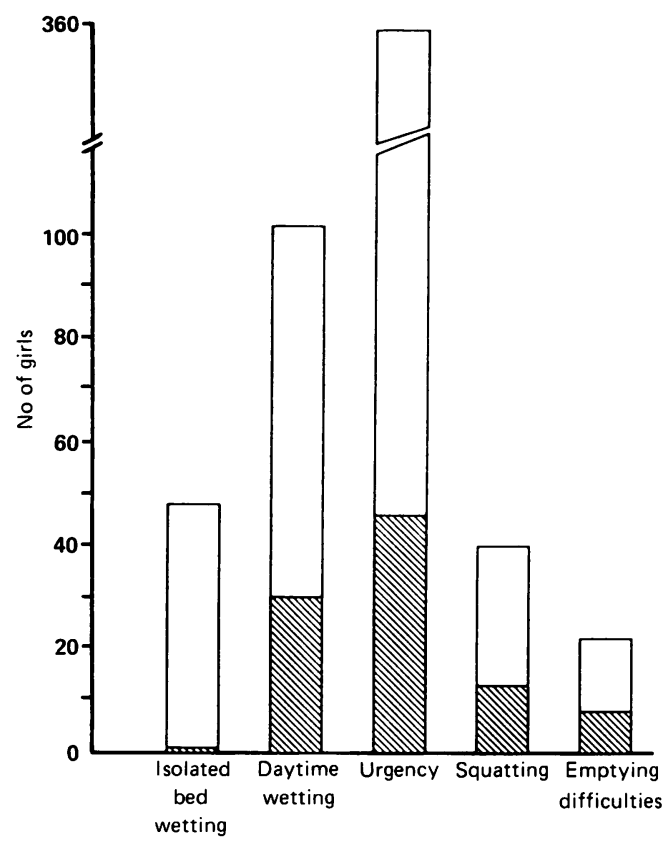

Figure 1 Proportion of girls reporting current symptoms with a history of previous urinary infection (hatched area).

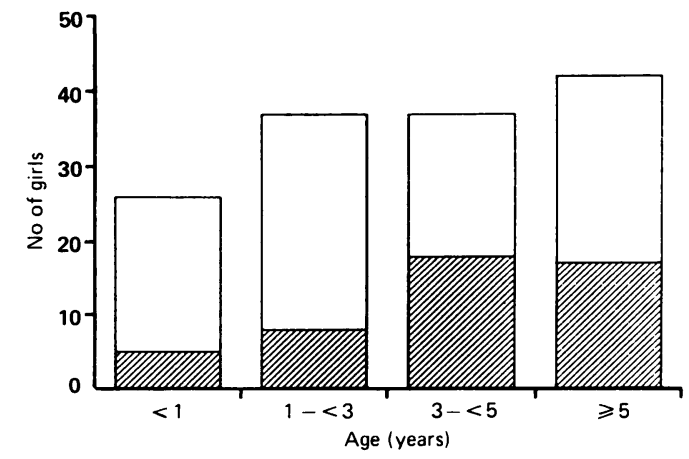

Figure 2 Number of girls with previous urinary infections according to age at the time of first known infection. The hatched areas indicate girls reporting symptoms suggestive of bladder dysfunction at 7 years of age. 
RECURRENCE OF INFECTION AND BLADDER SYMPTOMS

Fifty seven girls (39\%) and four boys (13\%) had had recurrent infections, and these were not related to age at the time of diagnosis of the first urinary tract infection. Symptoms suggestive of bladder disturbance (incontinence, urgency, squatting, and emptying difficulties) at 7 years of age were reported in $23(40 \%)$ of the girls with recurrences compared with 27 (26\%) in those with single episodes of infection; this difference is not significant.

\section{Discussion}

In this study of 7 year old Swedish children, a history of previous urinary tract infection was verified in 145 of the 1719 girls $(8.4 \%)$ and 32 of the 1834 boys $(1 \cdot 7 \%)$. These figures are higher than previously reported among similar children. In an epidemiological study of children with symptomatic urinary infection in Göteborg in 1960-6, Winberg et al recorded an overall morbidity of $2.8 \%$ in girls and $0.7 \%$ in boys up to 11 years of age. ${ }^{10}$ Our higher figures are, however, corroborated by another recent study from Göteborg in which acute pyelonephritis was found in $3 \cdot 1 \%$ of the girls and $1.0 \%$ of the boys up to the age of 6 years. ${ }^{11}$ This high detection rate probably reflects the increased awareness among the population and the physicians, and the common habit of culturing urine routinely in feverish infants and young children.

This study shows a clear association between the presence of bladder symptoms and a history of bacteriologically verified urinary infections in girls. Those who had had previous urinary infections reported significantly more symptoms suggestive of dysfunction of the lower urinary tract than those who had not. As many as one third of the girls who complained of daytime wetting, squatting, or emptying difficulties had had at least one episode of urinary infection in the past.

In contrast, girls with isolated bed wetting were at low risk of urinary infection; they also had normal frequency of micturition. This suggests that children with isolated bed wetting constitute a separate group from those who have symptoms during the day. The distinction is important, because the need for investigation of the urinary tract is highest among those with daytime symptoms, especially when combined with a history of urinary infections.

The age at which the first infection was diagnosed was of importance in the incidence of bladder symptoms. Girls who were over 3 years old at the time of their first infection had significantly more symptoms suggestive of bladder dysfunction at the age of 7 ; such an association was not found among girls whose urinary infections started when they were younger. Among boys there was no statistical association between symptoms and previous urinary infection. One probable explanation is the young age at which the boys had their first infection (median 0.8 years compared with 4.0 years in girls).

What is the basis for the association between urinary tract infection and bladder dysfunction? Which comes first? The design of this investigation did not allow us to evaluate the relative importance of these factors. It may be that an infection of the urinary tract during the period when bladder control is becoming established is a potential threat to the normal development of this control. Pain caused by urogenital inflammation may lead to a suppression of micturition resulting in disturbed function of the lower urinary tract and subsequently to an increased susceptibility to bacterial colonisation. On the other hand, dysfunction may be the first event. We often see patients who seem to have a primary 'hold' pattern affecting both the bowel and the bladder. This can lead to inefficient emptying of the bladder with residual urine and an inability to eliminate ascending bacteria.

Whatever the causal relationship may be, regular and complete emptying of the bladder and regular bowel habits are important in the prevention of urinary tract infections.

We thank the school nurses in Göteborg for their help and NilsGunnar Pehrsson for expert statistical guidance. This work was supported by Vilhelm and Martina Lundgren's Foundation fo Research and the First of May Flower Annual Campaign for Children's Health.

1 Cox CE, Hinman Jr F. Experiments with induced bacteriuria, vesical emptying and bacterial growth on the mechanisms of bladder defence to infection. 7 Urol 1961;86: $739-48$.

2 Lindberg U, Bjure J, Haugstvedt S, et al. Asymptomatic bacteriuria in schoolgirls. III. Relation between residual urine volume and recurrence. Acta Paediatr Scand 1975;64: volume $437-40$.

3 Lidefelt KJ, Erasmie U, Bollgren I. Residual urine in chil dren with acute cystitis and in healthy children: assessment dren with acute cystitis and in healthy child

4 Koff SA, Lapides J, Piazza DH. Association of urinary tract infection and reflux with uninhibited bladder contractions infection and reflux with uninhibited bladder contractions and volun $373-6$.

5 Dodge WF, West EF, Bridgforth EB, et al. Nocturnal enuresis in 6- to 10 year-old children-correlation with bacteruria, proteinuria and dysuria. $A m \mathcal{f}$ Dis Child 1970;120:32-5.

6 Sørensen K, Lose G, Nathan E. Urinary tract infections and diurnal incontinence in girls. Eur $\mathcal{F}$ Pediatr 1988;148: 146-7.

7 Hellström A-L, Hanson E, Hansson S, et al. Incontinence and micturition habits in 7-year-old Swedish school entrants. Eur $\mathcal{F}$ Pediatr 1990;149:434-7.

8 Vincent SA. Postural control of urinary incontinence, the curtsy sign. Lancet 1966;ii:631-2.

9 Jodal U, Lindberg U, Lincoln K. Level diagnosis of symptomatic urinary tract infections in childhood. Acta Paediatr Scand 1975;64:201-8.

10 Winberg J, Andersen HJ, Bergström T, et al. Epidemiology of symptomatic urinary tract infection in childhood. Acta of symptomatic urinary tract infection
Paediatr Scand $1974 ; 252$ (suppl): $1-20$.

11 Mårild S. Aspects of pathogenesis and renal development in childhood pyelonephritis. Göteborg: Vasastadens bokbinderi AB, 1989. (Thesis.) 